\title{
Study on water-use quotas for public institutions in China - Taking government agency as an example
}

\author{
Zhang Yu-bo ${ }^{1,2}$, Lin Ling ${ }^{1}$, Hu Hong-ying ${ }^{2}$, Bai Xue ${ }^{1 *}$ \\ ${ }^{1}$ China National Institute of Standardization, No.4 Zhichun Road, Haidian District, Beijing, 100191 \\ ${ }^{2}$ School of Environment, Tsinghua University, Haidian District, Beijing, 100084
}

\begin{abstract}
The shortage of water resources has become a critical factor that restricts China's economic and social development. Given that the numerous public institutions in China operate with large amounts of personnel, they consume massive water. Thus, the corresponding water-use quota was urgently needed. This paper explored setting quotas for governmental agencies in north and south district in China, adopting the quota level method. And comparisons between the results and the current national water-use quota and local water-use quota were carried out.
\end{abstract}

\section{Introduction}

Water resources in China are unevenly distributed in seasons and geographical dimensions, making China, with an increasing population, face a long term water shortage. This shortage has become a restricting factor for economic and social development hereby.

The public institutions consist of the government agencies, government-sponsored institutions and

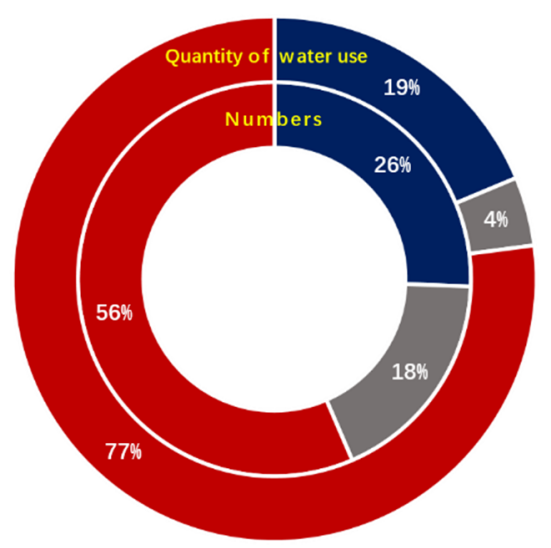

government-sponsored incorporations in China. The government agencies are established in central, provincial, municipal, county, and town levels, taking nearly $26 \%$ in the public institutions (Figure 1). According to the "Statistical Communique of the People's Republic of China on National Economic and Social Development 2018" and "China Water Resources Bulletin 2018", the public institutions consumed 123,290,000 cubic metres of water, among which the government agencies consumed $19 \%$ of water (Figure 1).

Figure 1. Numbers and water-use quantities for different public institutions of China in 2018

The quantity of water used for public institutions gradually reduced in recent years (Figure 2), and it took 14.3 percent of the national domestic water in 2018. An investigation on water consumption of 18 government agencies (Beijing) revealed that the average yearly water consumption was $1.7 \sim 1.8$ million cubic metres for organs at state and municipal levels, and 400 thousand cubic metres for organs at district levels [1]. For some organs, car washing, bathing, and some other activities consumed extensive water. Those administrative organs have a great water saving potential regarding poor water management; thus, a national water-use quota might vastly enhance water efficiency. If numerous government agencies show passion and commitment to water saving, signal and model effect might inspire the whole society on water-saving.

*Corresponding author’s e-mail: baixue@cnis.ac.cn 


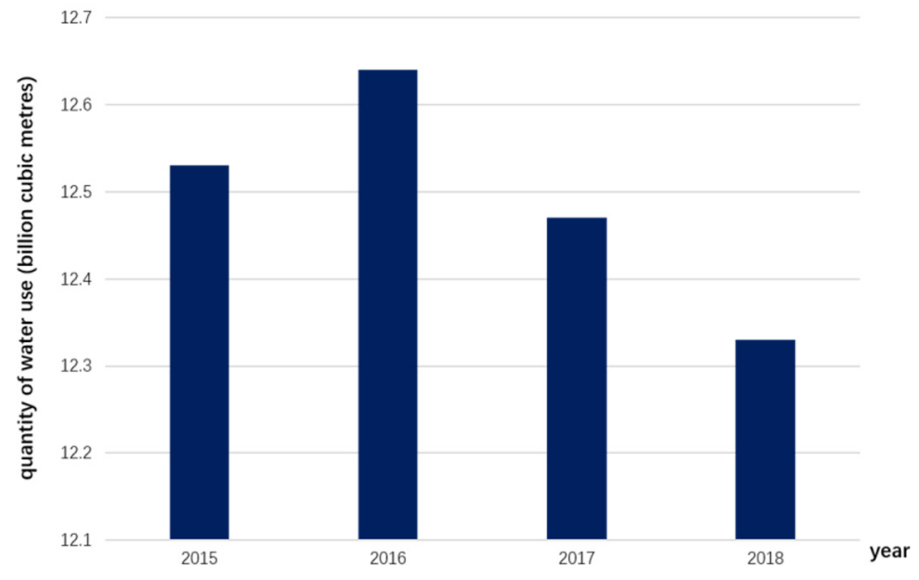

Figure 2. Quantities of water use for public institutions in recent years

\section{Water-use structure and provincial quotas}

Water in the government agencies is mainly used for office, cafeteria, bathing room, heating and cooling system, green irrigating facility, and other functional sites. Survey [2] on typical executive agencies in Beijing revealed that wateruse quantities were positively related to the number of employees and building areas. The number of employees shows a better correlation with water-use than building areas. Water used for office, like flushing, washing, cleaning and drinking, was the primary part, taking 47 per cent of total water. Cafeteria and bathing consumed 20 per cent of the total each. Few agencies had self-built heating systems and central air conditioning systems, which spend about 8 per cent of water. The water used for green irrigation accounts for about 5 per cent of the total. There are several other uses, such as laundry and car washing, consuming minimal water. The primary water-using sectors for the administrative organs are shown in Figure 3.

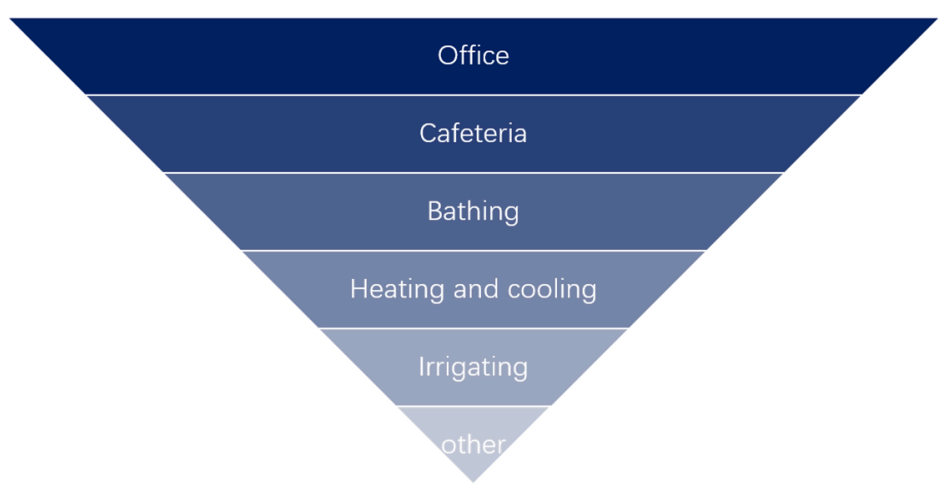

Figure 3. Typical water structure of administrative organs

Government at each level in China has been attaching importance to the compilation of water quota standards. Some provincial administrative regions have compiled local standards for water quotas in production and various living fields.

In term of government agency water-use, a total of 29 provincial administrative regions (autonomous regions and municipalities directly under the central government) have set water quotas for government agencies themselves as well [3]. Different provincial administrative regions stipulated different water-use quota values according to diverse water conditions. The provincial water-use quotas for government agencies were shown in Figure 4. Among these local quotas, some provincial administrative regions provided more detailed categories according to water consumption characteristics, and some of the stipulated water-consumption quotas for different administrative levels. 


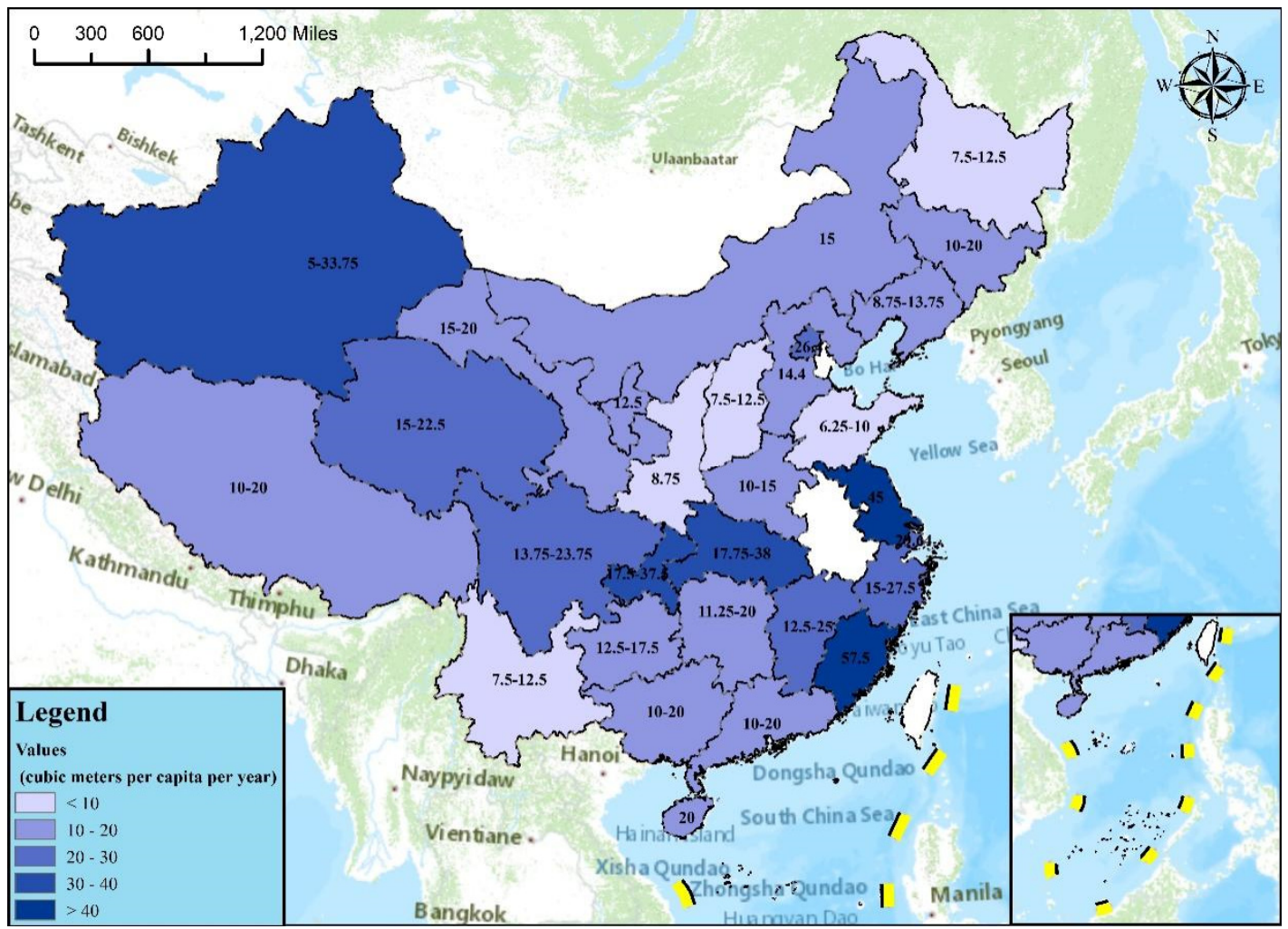

Figure 4. Water consumption quotas of different provincial administrative regions in China.

Although 29 provincial administrative regions have set water quotas for government agencies, the dispersed quota system had some drawbacks. First, those quotas lacked authority as local standards, difficult to promote and put into practice. Second, various classification emphasised the difference between each province but at the expense of weakening comparability. Therefore, it is necessary to discuss a national water-use quota to address those deficiencies.

\section{Material and method}

\subsection{Samples}

Given the significant differences in climate between north and south regions, this paper separately discussed wateruse quota in China's north and south district $[4,5]$. The north district consists of 14 provincial administrative regions including Beijing, Tianjin, Hebei, Shanxi, Inner Mongolia, Liaoning, Jilin, Heilongjiang, Shandong, Henan, Shaanxi, Gansu, Ningxia, and Xinjiang; The south district consists of the rest 17 provincial administrative regions. Taiwan, Hong Kong and Macau were not discussed in this paper.

We collected 118 water-use samples from 6 provincial regions of the north district and 61 samples from 5 provinces of the south district, involving quantities of water-use per capita per year based on the annual water consumption and the number of employees.

\subsection{Quota level method}

The water-use quota is the basis of indicators for water management and water-saving assessment in China. Due to the vast number and the limited water metering and management level of public institutions, water-use quotas were usually established by quota level method, which was put forward by Zhou et al. for a rational analysis of data with limited quantity and quality[6]. This method is practical and widely adopted in China. This research attempted to establish a water-use quota for government agencies in north and south districts using this method, in which normally distributed data were analysed. Quota level tables were compiled by calculating the water-use quota corresponding to different probabilities. The excellent and fundamental quota values of water-use were determined by choosing different suitable quota levels (probabilities).

For both of the northern and the southern data sets in this study, the skewness and kurtosis test for normality is described by the STATA [7], and the average values $(\mu)$ and the standard deviations $(\sigma)$ were calculated. If the analysed data were normally distributed, water consumption data corresponding to a specific level was determined according to the general principle for the normal distribution in mathematical statistics (Formula 1), forming a quota level table.

$$
\ln Q=\mu+\sigma \cdot Z_{p}
$$

Where $Q$ represents the quota value (in cubic metres per capita per year); $\mathrm{Zp}$ represents the probability density 
value of the standard normal distribution when the cumulative probability is $(1-p)$, corresponding to the probability of samples not meeting the quota value.

\section{Results}

\subsection{Test for lognormalities}

After log-transformation of the water-use data from the North and South of China, the skewness and kurtosis tests were respectively described in the STATA. The results were displayed in table 1 . As $\mathrm{P}$ values $>0.05$, the data's logarithm is normally distributed. The normal distribution histograms were illustrated in Figures 5 and 6.

Table 1. Skewness/Kurtosis tests for lognormalities of water-use data of government agencies in northern and southern China

\begin{tabular}{|c|c|c|c|c|c|}
\hline & Obs & $\begin{array}{c}P \\
\text { (Skewness) }\end{array}$ & $\begin{array}{c}P \\
\text { (Kurtosis) }\end{array}$ & $\begin{array}{c}\text { adj } \\
\text { chi2(2) }\end{array}$ & $\begin{array}{c}P> \\
\text { chi2 }\end{array}$ \\
\hline $\begin{array}{c}\text { North } \\
\text { district }\end{array}$ & 118 & 0.1656 & 0.1581 & 4.01 & 0.1350 \\
\hline $\begin{array}{c}\text { South } \\
\text { district }\end{array}$ & 61 & 0.5328 & 0.0604 & 4.08 & 0.1298 \\
\hline
\end{tabular}

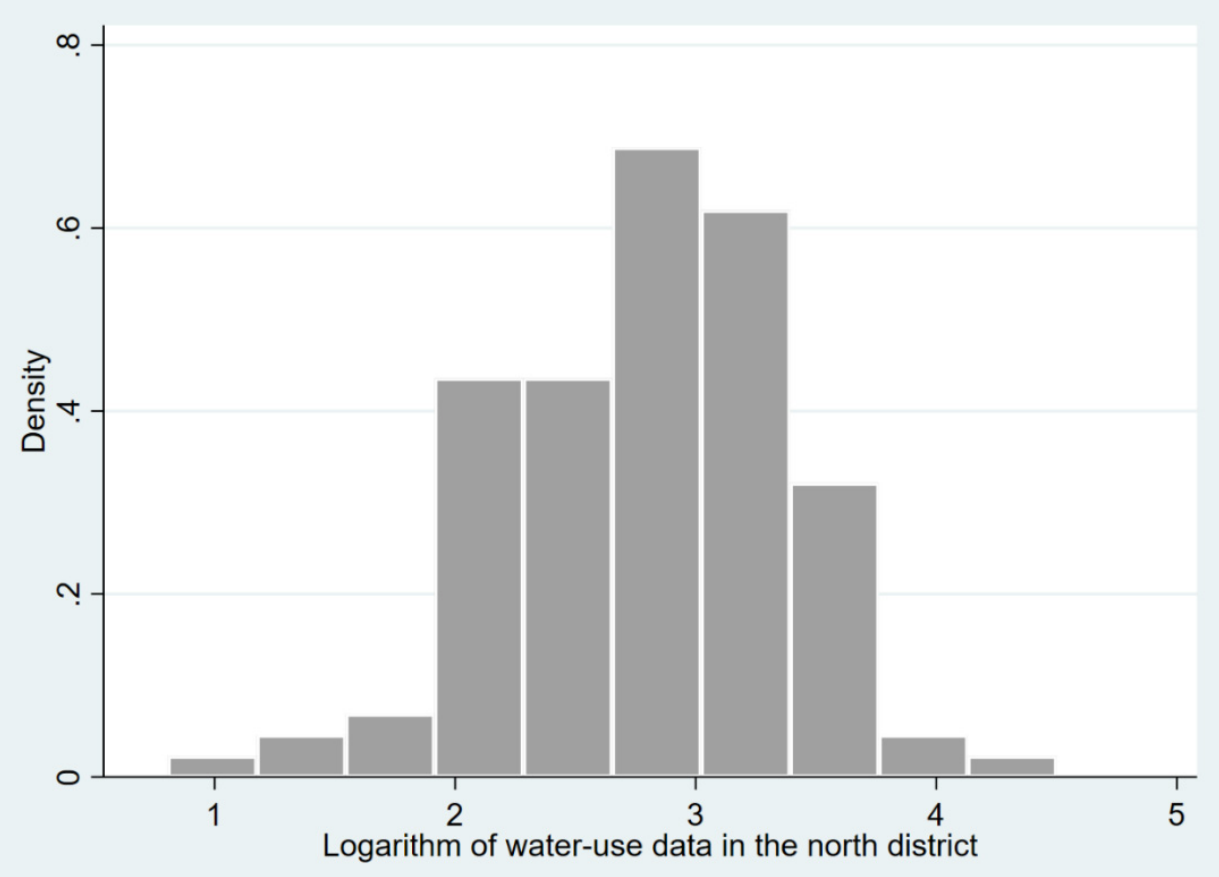

Figure 5. The normal distribution histograms of logarithm of water-use data in the north district.

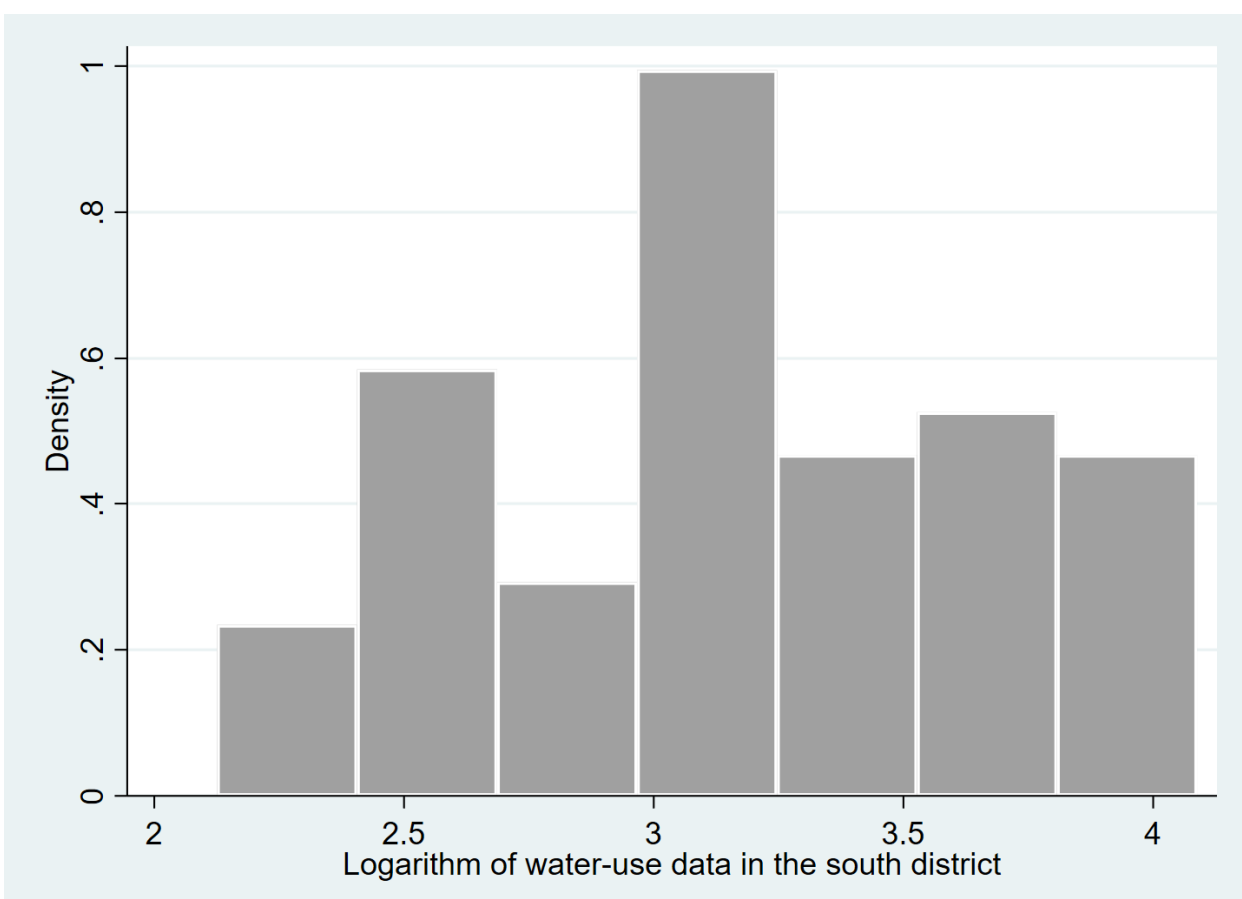

Figure 6. The normal distribution histograms of logarithm of water-use data in the south district. 


\subsection{Preparation of quota level tables}

The average values and the standard deviations for the logarithm of government agencies water-use data in northern and southern China were calculated via the STATA. The results were illustrated in Table 2 and Table 3. We calculated the probability density values of the lognormal distributions with Formula 1. After another logtransformation, the corresponding quota values at different quota levels generated. We presented the quota level tables for northern and southern China in Tables 3 and 4.

Table 2. The average values and the standard deviations for the logarithm of water-use data from the northern and the southern government agencies

\begin{tabular}{|c|c|c|c|c|c|}
\hline & Obs & $\begin{array}{c}\text { average } \\
\text { value }(\mu)\end{array}$ & $\begin{array}{c}\text { standard } \\
\text { deviation } \\
(\sigma)\end{array}$ & Min & Max \\
\hline $\begin{array}{c}\text { North } \\
\text { district }\end{array}$ & 118 & 2.821577 & 0.5899648 & 0.8064759 & 4.49981 \\
\hline $\begin{array}{c}\text { South } \\
\text { district }\end{array}$ & 61 & 3.163932 & 0.5163682 & 2.125796 & 4.087861 \\
\hline
\end{tabular}

Table 3. The quota values corresponding to different quota levels for government water-use in North of China

\begin{tabular}{|c|c|c|c|}
\hline Quota level & $\begin{array}{c}\text { Quota value } \\
\text { (in cubic } \\
\text { metres per } \\
\text { capita per } \\
\text { year) }\end{array}$ & Quota level & $\begin{array}{c}\text { Quota value } \\
\text { (in cubic } \\
\text { metres per } \\
\text { capita per } \\
\text { year) }\end{array}$ \\
\hline 0 & 1.68323 & 0.5 & 16.80333 \\
\hline 0.05 & 6.366723 & 0.55 & 18.08934 \\
\hline 0.1 & 7.887207 & 0.6 & 19.50826 \\
\hline 0.15 & 9.140667 & 0.65 & 21.0882 \\
\hline 0.2 & 10.22491 & 0.7 & 22.90393 \\
\hline 0.25 & 11.2836 & 0.75 & 25.0232 \\
\hline 0.3 & 12.32766 & 0.8 & 27.61412 \\
\hline 0.35 & 13.38909 & 0.85 & 30.88963 \\
\hline 0.4 & 14.47345 & 0.9 & 35.79871 \\
\hline 0.45 & 15.60875 & 0.95 & 44.34807 \\
\hline
\end{tabular}

Table 4. The quota values corresponding to different quota levels for government water-use in South of China

\begin{tabular}{|c|c|c|c|}
\hline Quota level & $\begin{array}{c}\text { Quota value } \\
\text { (in cubic } \\
\text { metres per } \\
\text { capita per } \\
\text { year) }\end{array}$ & Quota level & $\begin{array}{c}\text { Quota value } \\
\text { (in cubic } \\
\text { metres per } \\
\text { capita per } \\
\text { year) }\end{array}$ \\
\hline 0 & 3.158496 & 0.5 & 23.66346 \\
\hline 0.05 & 10.11993 & 0.55 & 25.24121 \\
\hline 0.1 & 12.20625 & 0.6 & 26.9659 \\
\hline 0.15 & 13.88821 & 0.65 & 28.868 \\
\hline 0.2 & 15.31986 & 0.7 & 31.0322 \\
\hline
\end{tabular}

\begin{tabular}{|c|c|c|c|}
\hline 0.25 & 16.69958 & 0.75 & 33.53134 \\
\hline 0.3 & 18.04446 & 0.8 & 36.5512 \\
\hline 0.35 & 19.39723 & 0.85 & 40.31905 \\
\hline 0.4 & 20.76546 & 0.9 & 45.8748 \\
\hline 0.45 & 22.18433 & 0.95 & 55.33235 \\
\hline
\end{tabular}

\subsection{Determination of quota levels and values}

The Chinese national standard "Technical guideline of stipulation of norm of water intake (GB/T 32716-2016)" recommended quota levels 0.2 and 0.8 to calculate excellent and fundamental values respectively. We established the quota level and values (Table 5) according to this standard.

Table 5. The fundamental and excellent quota values for government water-use in South of China (in cubic metres per capita per year)

\begin{tabular}{|c|c|c|}
\hline & Fundamental value & Excellent value \\
\hline (Quota level) & $(0.8)$ & $(0.2)$ \\
\hline North district & 27.61 & 10.25 \\
\hline South district & 36.55 & 15.32 \\
\hline
\end{tabular}

\section{Conclusion and discussion}

As massive water in China consumed by large amounts of public institutions, the corresponding water-use quota was desperately needed to guide those water management. In this paper, we adopted the quota level method, which was suitable for analysing data with limited quantity and quality, to analyse the water-use quota of the government agencies in China's north and south districts rationally. After mathematically processing with 118 water-use samples from the north district and 61 samples from the south district, we generated the quota values corresponding to different quota levels for government in both North and South of China. According to the quota levels recommended in the GB/T 32716-2016, the fundamental values and excellent values for China's north and south districts were determined (Table 5).

In 2019, the Ministry of Water Resources of the People's Republic of China issued national water-use quotas for government agencies [8], including the excellent and fundamental values for China's north and south district. The ministry would use the fundamental values for the daily water management and water-saving assessment to various agencies. They will use the excellent ones to appraise water resources, approve water intake permit, and evaluate new projects' water-saving status. In this issued quotas, the excellent and fundamental values were 10 $\mathrm{m} 3 /(\mathrm{c} \cdot \mathrm{a})$ and $25 \mathrm{~m} 3 /(\mathrm{c} \cdot \mathrm{a})$ respectively for agencies in the north district, and $15 \mathrm{~m} 3 /(\mathrm{c} \cdot \mathrm{a})$ and $38 \mathrm{~m} 3 /(\mathrm{c} \cdot \mathrm{a})$ cubic metres per capita per year respectively for those in the south. The excellent ones from this research were close to 
those in the document. The fundamental value for the south district in this paper was smaller $(36.55 \mathrm{~m} 3 /(\mathrm{c} \cdot \mathrm{a}))$, and that for the north district was higher $(27.61 \mathrm{~m} 3 /(\mathrm{c} \cdot \mathrm{a}))$. The sampling may cause discrepancy. Of course, as water resources in the north were less than the south, it is reasonable to set a more stringent fundamental value for the north district.

We presented the comparisons between our quota values with the current provincial water-use quotas in
Figures 7 and 8 . All local administrative regions passed the fundamental value, and $23.1 \%$ passed the excellent value in the north district. In the south of China, $23.5 \%$ of provinces passed the excellent value, and $88.2 \%$ gave the fundamental one. Water management in local regions that have not passed the fundamental values might revise local water-use quotas for more practical use after comprehensive research and discussion.

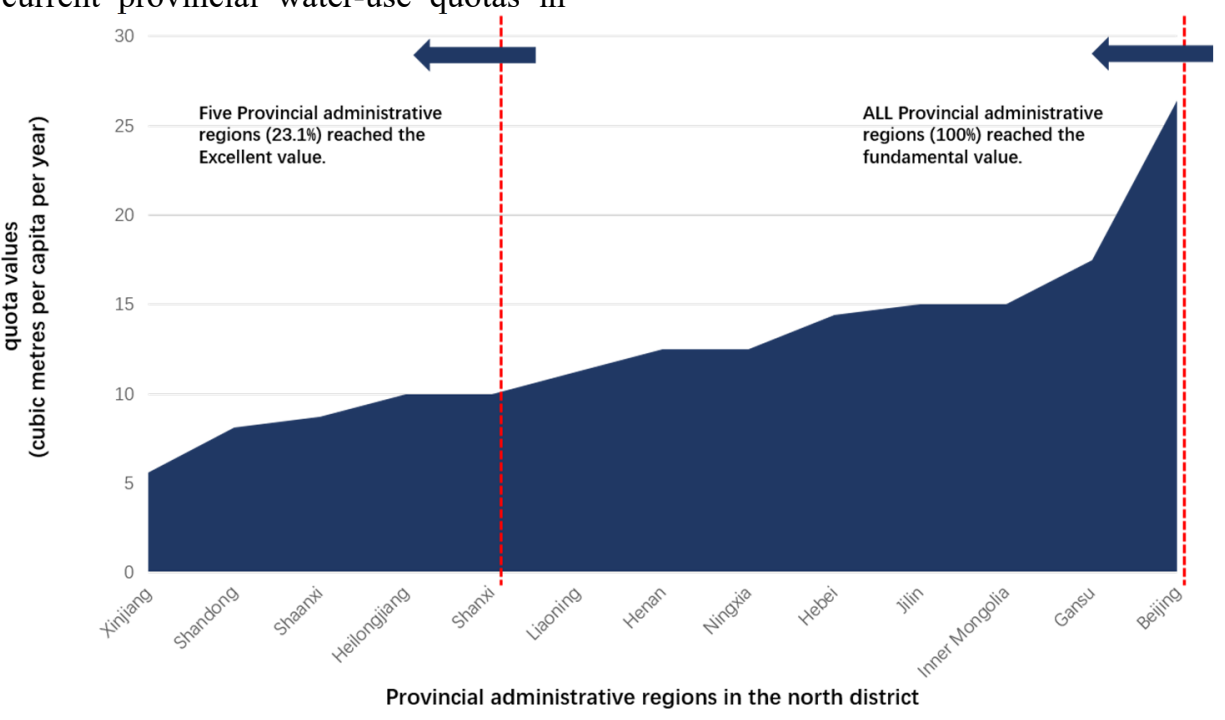

Figure 7. Comparison of the quota value with the provincial quotas in the north district.

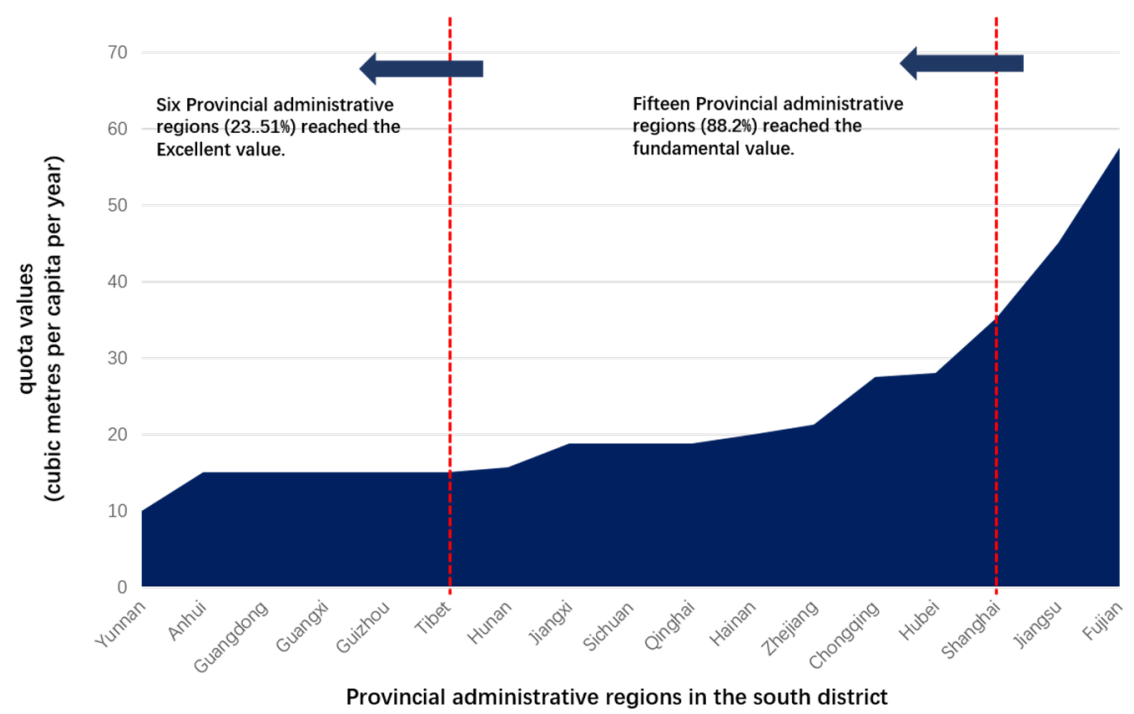

Figure 8. Comparison of the quota value with the provincial quotas in the south district.

\section{Acknowledgements:}

This research is supported by the Science and Technology Plan Project of the State Administration for Market Regulation (NO. 2020MK168) and the Dean's Fund of China National Institute of Standardization (NO. 542020Y7456).

\section{References:}

1. Hu Ya-jie, Che Jian-ming, Ma Jing, Hao Rui-rui,
Zhang Chun-ling, Gao Yuan, Chen Zheng, Liu Wei. Water consumption of Beijing's government departments and institutions $[\mathrm{J}]$. China Water Resource, 2014, (17), 22-24.

2. Weng Jian-wu, Chen Yuan-sheng. Water consumption analysis and water-saving measurements of Beijing administrative organizations [J]. Water \& Wastewater Engineering. 2009, 35(1):16-20.

3. Water Resource Management Center, Ministry of Water Resources. Compilation of regional quotas of China [Z]. 2017-10.

4. Ministry of Water Resources of the People's Republic 
of China. The Ministry of Water Resources on the implementation of the most stringent water resources management system assessment in 2019 [Z]. 2019-06.

5. Ministry of Water Resources of the People's Republic of China, Notice on carrying out the construction of water-saving society in county areas [Z]. 2017-05.

6. Zhou Zhi-yong, Fu Xiang-zhao, Liu Jun-yue, He Hua. Establishment of energy consumption quota for public buildings based on statistical data [J].Gas \& Heat. 2009, 29(12): A14-A17.

7. Ma Hui-hui. STATA Statistical analysis and application [M]. Beijing: Publishing House of Electronics Industry, 2016.

8. Ministry of Water Resources of the People's Republic of China. Notice on the issuance of water-use quotas for three service including hotels [Z]. 2019-10. 